\title{
Microbial Landscape of the Grapevine Endosphere in the Context of Pierce's Disease
}

\author{
Elizabeth Deyett, Department of Botany and Plant Sciences, University of California, Riverside 92521; M. Caroline \\ Roper, Department of Plant Pathology and Microbiology, University of California, Riverside 92521; Paul Ruegger, \\ Department of Plant Pathology and Microbiology, University of California, Riverside 92521; Jiue-In Yang, \\ Department of Plant Pathology and Microbiology, National Taiwan University, Taipei 106, Taiwan; James \\ Borneman, Department of Plant Pathology and Microbiology, University of California, Riverside 92521; and \\ Philippe E. Rolshausen, ${ }^{\dagger}$ Department of Botany and Plant Sciences, University of California, Riverside 92521
}

Accepted for publication 17 August 2017.

\section{ABSTRACT}

Microbial community structure and composition in the plant vascular endosphere has not been studied extensively especially in the context of vascular diseases. Pierce's disease (PD) of grapevine is caused by Xylella fastidiosa, a xylem-limited bacterium. In PD-impacted vineyards, there are observations of vines that remain asymptomatic despite being under high disease pressure. Because these vines are clonal, we hypothesized that the microbial community inhabiting the grapevine vascular endosphere is a major contributor to the disease escape phenotype. We used a next-generation sequencing Illumina MiSeq-based platform to characterize the bacterial and fungal microbiome residing in the cane endosphere of grapevine that displayed severely symptomatic, to mildly symptomatic or asymptomatic disease phenotypes. Our results provide evidence that the endophytic grapevine microbial community is composed primarily of Proteobacteria and Ascomycota with Pseudomonodales and Pleosporales as the main bacterial and fungal orders, respectively. Endophytic Pseudomonas fluorescens and Achromobacter xylosoxidans showed significant negative correlations with $X$. fastidiosa titer. Our data suggest that the clustering of bacterial communities appeared to be driven by the abundance of both $P$. fluorescens and $X$. fastidiosa. $P$. fluorescens emerged as a potential driver of the disease-escape phenotype and a promising biological control agent of PD.

Additional keywords: Vitis vinifera.
Plants host a diverse community of microorganisms and the plant-associated microbiome is defined as the collection of all microbes associated with the rhizosphere (the soil-root interface), the phyllosphere (epiphytic, aerial surfaces), and the endosphere (internal tissues) (Turner et al. 2013). The structures of the tissuespecific communities can have shared members, but also support unique groupings of microbes within each of the tissue types or

${ }^{\dagger}$ Corresponding author: P. E. Rolshausen; E-mail: philrols@ucr.edu

Author contributions. E.D. made tables and figures, performed microbiome bioinformatic analyses, built phylogenetic analyses, BLAST sequences for unassigned taxa in NCBI and obtained NCBI sequence accession numbers. M.C.R. co-designed the research and co-wrote the manuscript. P.R. performed and co-designed some of the microbiome bioinformatic analyses. J.Y. processed plant samples and built Illumina libraries. J.B. coordinated and co-designed some of the microbiome analyses and designed and performed the chromosomal walking experiments. P.E.R. planned and designed the research, collected plant samples, and wrote the manuscript.

*The $\boldsymbol{e}$-Xtra logo stands for "electronic extra" and indicates that two supplementary figures and one supplementary table are published online.

(C) 2017 The American Phytopathological Society biocompartments (Compant et al. 2011; Martins et al. 2013). Many factors can shape the microbiomes of the rhizosphere, phyllosphere and endosphere. Rhizosphere microbiomes are derived from the soil and can be recruited by the plant host (Bais et al. 2006; Berendsen et al. 2012; Compant et al. 2010; Turner et al. 2013; van der Heijden and Schlaeppi 2015). The microbial community landscape of the root endosphere can also be derived from the rhizosphere (Turner et al. 2013), which further shapes the microbiome of the plant vascular system (Compant et al. 2010; van der Heijden and Schlaeppi 2015). In contrast, the phyllosphere is a transient environment with fluctuations in nutrient and water availability as well as extreme variations in temperature and ultraviolet radiation that all shape the microbial landscape on leaf surfaces (Rastogi et al. 2013; Vorholt 2012). Both rhizosphere and phyllosphere microbiomes are known to provide protection against plant pathogens through a variety of mechanisms ranging from niche displacement, production of antimicrobial compounds, and interference with microbial cell-cell signaling systems (Compant et al. 2010; Rastogi et al. 2013; Vorholt 2012). In addition, plant growth promoting bacteria in the rhizosphere, such as Pseudomonas or Bacillus spp., can activate induced systemic 
resistance (ISR) and sensitize the plant immune system for enhanced defense responses leading to systemic defense priming and tolerance to pathogen challenge (Bolwerk et al. 2003; Gruau et al. 2015; Kloepper et al. 1992; Pieterse et al. 2014).

Grapevine (Vitis vinifera L.) is an important agricultural crop worldwide. Grape berries are prized for their nutritional value as well as their oenological properties that contribute to high quality wine production. Thus far, studies on the microbial communities associated with $V$. vinifera grapevines have primarily focused on characterizing the communities that are present on epiphytic parts of the plant (leaves, berries, and roots) and the dynamics of these epiphytic microbiomes in response to external factors such as fungicide applications (Bokulich et al. 2014; Campisano et al. 2015; Perazzolli et al. 2014; Pinto et al. 2014; Zarraonaindia et al. 2015). Two recent studies have also looked at the impact of root and collar infection with Agrobacterium and the sap-feeding leafhopper Scaphoideus titanus on the endosphere bacterial community composition in grapevine (Faist et al. 2016; Lopez-Fernandez et al. 2017).

Pierce's disease (PD), caused by the Gram-negative, xylemlimited bacterium Xylella fastidiosa (Wells et al. 1987), is one of the major threats to grapevine production in the Americas (Roper and Lindow 2015; Varela et al. 2001). In addition, X. fastidiosa has recently been reported in olives in Italy and ornamentals in France iterating the importance of $X$. fastidiosa as a global re-emerging pathogen (Almeida and Nunney 2015; Saponari et al. 2013). The bacterium is limited to the xylem tissue compartment where it multiplies to high titer, which leads to vascular occlusion caused by bacterial aggregates, bacterial exopolysaccharide, and hostproduced tyloses (Roper et al. 2007; Sun et al. 2013). External symptoms of PD include leaf scorching, irregular wood maturation, raisining of berries, and overall stunting (Hopkins and Purcell 2002). Once infected, vines can succumb to the disease in as little as 2 years, and all $V$. vinifera cultivars are susceptible to PD. $X$. fastidiosa is exclusively vectored by xylem-feeding insects belonging to the families Cicadellidae and Cercopidae, primarily sharpshooters. Insecticide sprays are the primary means of management of the disease aside from severe pruning or rogueing of infected vines. Currently, there are no sustainable control measures for PD and, hence, this disease remains a serious threat to California and worldwide grape production, and results in millions of dollars of annual economic losses related to damage to existing vineyard plantings, vector and disease management, and replanting (Alston et al. 2013; Tumber et al. 2014).

In vineyards under high PD pressure (Supplementary Fig. S1), individual asymptomatic or mildly symptomatic vines can be found among many heavily infected vines (Darjean-Jones 2004) and are referred to as disease escape vines. All grapevines in vineyard blocks are clonal, which suggests a nongenetic mechanism for the observed host tolerance to PD. Because of the diversity of microbes in any given ecosystem and the array of biological functions inherent to microbes, we based this study on the hypothesis that the observed PD tolerance is driven by the endophytic microorganisms living in the plant endosphere that either directly or indirectly suppress the growth of $X$. fastidiosa in the xylem. An understanding of how endophytic microbial communities modify plant health by affecting disease outcomes through antagonizing or facilitating disease (Busby et al. 2016), particularly for vascular-dwelling pathogens, is just beginning. Many comprehensive plant microbiome studies have focused on the bacterial communities and from this a breadth of valuable knowledge about how bacterial communities interact with plants has been derived (Sessitsch et al. 2012). Fungi are also important interactors in the context of the plant-microbiome holobiont. The initial goal of this study was to characterize the core microbial structure and composition of the grapevine vascular endosphere including both bacteria and fungi. Stemming from that information, the second objective was to gain a better understanding of the microbial community structure under disease pressure and, in particular, in vines that escape PD despite being in areas of high disease pressure. The long-term goal is to develop this information into translational studies that test the application of endogenous microbes as tools for sustainable crop protection.

\section{MATERIALS AND METHODS}

Plant sample collection. Samples were collected from a total of ten vineyards in California (Table 1). Five commercial vineyards with cultivars, Syrah, Petite Sirah, Chardonnay, Tempranillo, and Mourvedre were located in Temecula Valley, in southern California. This hot and arid viticulture area has been severely impacted by PD, because of the introduction of the invasive glassy winged sharpshooter (GWSS), Homalodisca vitripennis (Blua et al. 1999). In addition, four commercial vineyards with cultivars, Merlot, Riesling, and Chardonnay (two vineyards) were located in Napa Valley in northern California. This viticultural area is wetter and cooler than the southern area. In northern California, X. fastidiosa is commonly vectored by the California native blue-green sharpshooter (BGSS), Graphocephala atropunctata. Historically, the incidence of PD in northern California vineyards has been primarily isolated to vineyards adjacent to riparian areas, which serve as reservoirs of the BGSS (Hopkins and Purcell 2002). These areas have high incidences of PD and are referred to as PD hotspots. Because of the distinctly different feeding and breeding behavior of the GWSS in southern California, entire vineyards are impacted with severe PD rather than being isolated to hotspots (Perring et al. 2001). In northern California, disease escape and infected vines were sampled from within PD hotspots and in southern California disease escape and infected vines were sampled from within vineyards highly impacted with PD (adjacent to citrus groves that serve as reservoirs for the GWSS). Grapevine cane tissue was sampled over 3 years in August/September, when grapevines express typical PD symptoms. A total of 68 samples were collected from those nine vineyards in Napa or Temecula (Table 1), with half from grapevines expressing PD symptoms (PD-symptomatic) and the other half from healthy to mildly symptomatic grapevines (PD-escape). Canes were randomly selected from PD-symptomatic grapevines and from PD-escape grapevines. Following sampling, canes were stored in a cooler on

\begin{tabular}{|c|c|c|c|c|}
\hline \multicolumn{5}{|c|}{$\begin{array}{l}\text { TABLE } 1 \\
\text { Scheme of the } 73 \text { grapevine cane samples collected }\end{array}$} \\
\hline Location & $\begin{array}{l}\text { Number of } \\
\text { vineyards }\end{array}$ & Cultivar & $\begin{array}{l}\text { Year } \\
\text { collected }\end{array}$ & $\begin{array}{l}\text { Number of } \\
\text { samples }\end{array}$ \\
\hline \multirow[t]{5}{*}{ Temecula } & 5 & Chardonnay & 2013 & 10 \\
\hline & & Mouvedre & 2013 & 10 \\
\hline & & Petite Sirah & 2013 & 10 \\
\hline & & Syrah & 2010 & 12 \\
\hline & & Tempranillo & 2013 & 10 \\
\hline \multirow[t]{3}{*}{ Napa } & 4 & Chardonnay & 2011 & 8 \\
\hline & & Merlot & 2011 & 4 \\
\hline & & Riesling & 2011 & 4 \\
\hline \multirow[t]{2}{*}{ FPS Davis $^{a}$} & 1 & Chardonnay & 2014 & 2 \\
\hline & & Merlot & 2014 & 3 \\
\hline
\end{tabular}


ice and brought back to the laboratory. In addition, five 1-year-old grape cuttings cultivar Chardonnay (two samples) and Merlot (three samples) originating from one vineyard at the Foundation Plant Services (FPS), UC Davis, were included in our pool of samples. These FPS samples are certified to be free of $X$. fastidios $a$ and were mainly used to build the endosphere microbiome profile of grapevine canes and were not included in the Pearson correlation analyses. In the laboratory, one internode was harvested with sterile pruning shears from each cane. Internode samples were dipped in $100 \%$ ethanol and surface-sterilized by flaming. Subsequently, the bark was removed with a sterile blade and these debarked samples were stored at $-80^{\circ} \mathrm{C}$.
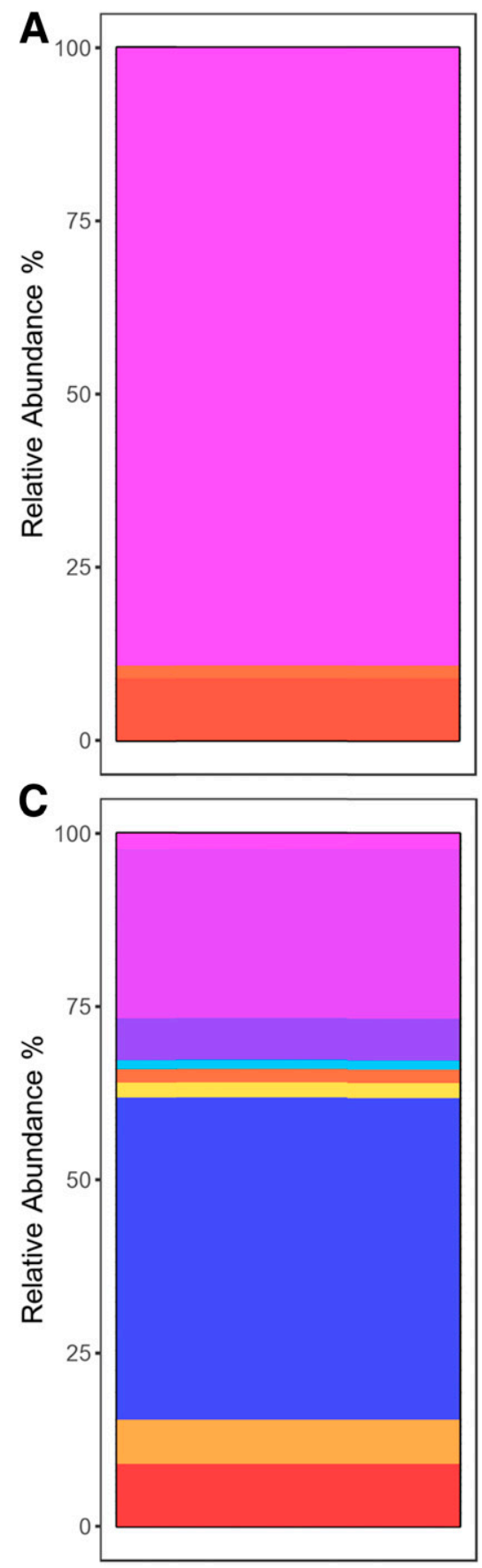

DNA extraction from debarked cane tissue. Frozen tissues were lyophilized for $36 \mathrm{~h}$ with a FreeZone 2.51 Benchtop Freeze Dry System (Labconco, Kansas City, MO). Following this, the samples were finely chopped with sterilized knives and ground at room temperature using a Retsch MM300 grinder (90 s, 25 oscillations per second) in a 35-ml stainless-steel grinding jar (Retsch, Haan, Germany) with $20 \mathrm{~mm}$ stainless steel balls as previously described (Pouzoulet et al. 2014). Total DNA was extracted from $50 \mathrm{mg}$ of dried tissue using a Qiagen DNeasy plant mini kit (Qiagen, Valencia, CA) according to manufacturer's instructions with the exception of using CTAB (hexadecyltrimethylammonium bromide, SigmaAldrich, St. Louis, MO) extraction buffer (Doyle and Doyle 1987)

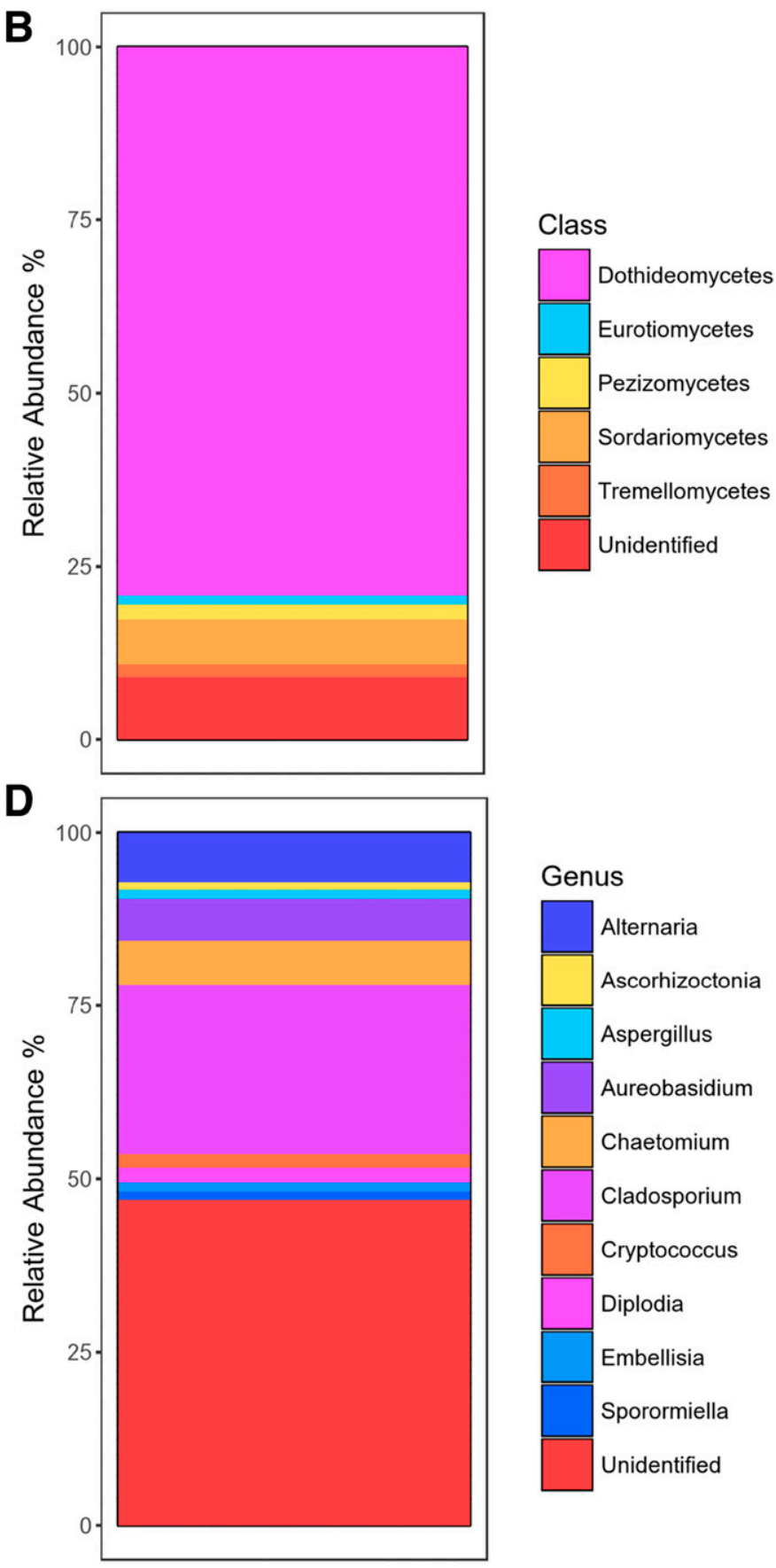

Fig. 1. Relative abundance (percent) of the fungal taxa inhabiting the grape vascular system endosphere: A, phylum; B, class; C, order; and D, genus. The operational taxonomic units (OTUs) that did not occur in at least $1 \%$ of the dataset were filtered out and the remaining OTUs are presented in relative abundance $(n=34)$. 
as the lysing buffer instead of the AP1 buffer provided with the kit. The DNA for all samples was aliquoted and stored at $-20^{\circ} \mathrm{C}$ before use.

Bacterial rRNA gene sequencing. Illumina bacterial 16S rRNA gene libraries were constructed as previously described (Ruegger et al. 2014). One-hundred-microliter amplification reactions were performed in a MJ Research PTC-200 thermal cycler (Bio-Rad Inc., Hercules, CA) containing $50 \mathrm{mM}$ Tris $(\mathrm{pH} \mathrm{8.3)}$, bovine serum albumin (BSA) at $500 \mu \mathrm{g} / \mathrm{ml}, 2.5 \mathrm{mM} \mathrm{MgCl} 2,250 \mu \mathrm{M}$ of each deoxynucleotide triphosphate (dNTP), $400 \mathrm{nM}$ of each PCR primer, $4 \mu$ l of DNA template, and 2.5 units of JumpStart Taq DNA polymerase (Sigma-Aldrich). In brief, the PCR primers $515 \mathrm{~F}$
(GTGCCAGCMGCCGCGGTAA) and 806R (GGACTACHVGG GTWTCTAAT) targeted the $16 \mathrm{~S}$ rRNA gene containing portions of the hypervariable regions V4 and V5, with the reverse primers including a 12-bp barcode (Caporaso et al. 2010). Thermal cycling parameters were $94^{\circ} \mathrm{C}$ for $5 \mathrm{~min} ; 35$ cycles of $94^{\circ} \mathrm{C}$ for $20 \mathrm{~s}, 50^{\circ} \mathrm{C}$ for $20 \mathrm{~s}$, and $72^{\circ} \mathrm{C}$ for $30 \mathrm{~s}$, and followed by $72^{\circ} \mathrm{C}$ for $5 \mathrm{~min}$. PCR products were purified using the MinElute 96 UF PCR Purification Kit (Qiagen).

DNA sequencing was performed using an Illumina MiSeq (Illumina, Inc, San Diego, CA). Clusters were created using template concentrations of $1.5 \mathrm{pM}$ and PhiX at $65 \mathrm{~K} \mathrm{~mm}^{-2}$ and 301 base read lengths were truncated after the 260th base where sequence quality
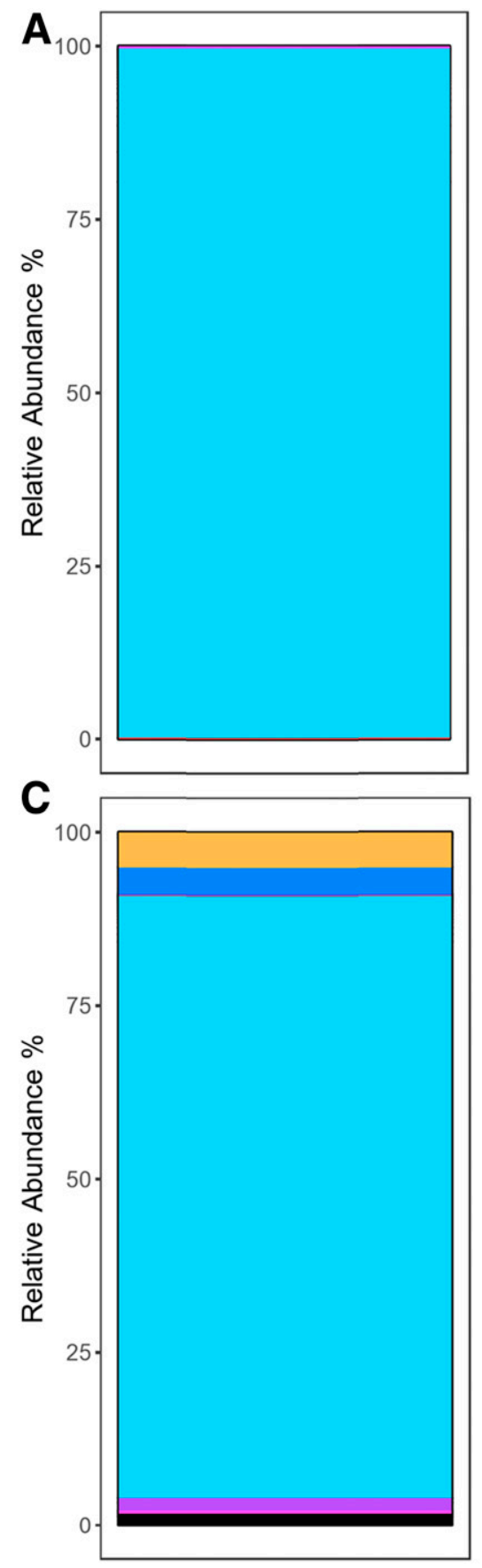

Fig. 2. Relative abundance (percent) of the bacterial taxa inhabiting the grape vascular system endosphere: A, phylum; B, class; C, order; and D, genus. The operational taxonomic units (OTUs) that did not occur in at least $1 \%$ of the dataset were filtered out and the remaining OTUs are presented in relative abundance $(n=72)$.
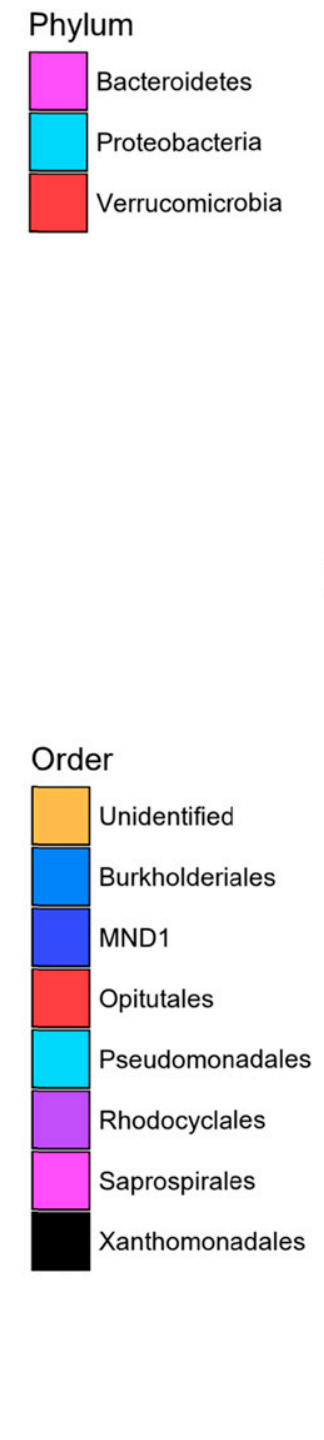

B
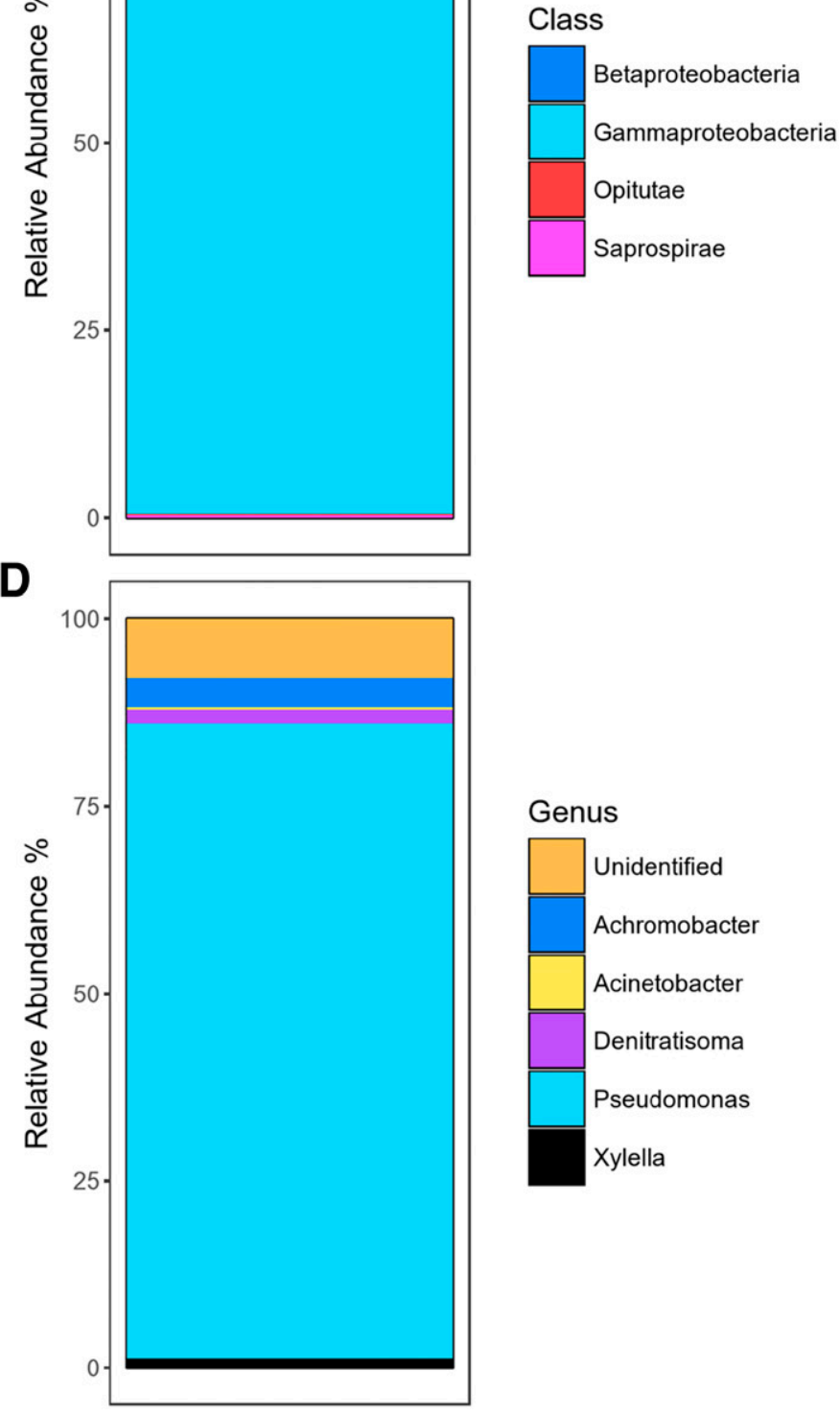

D

25 .

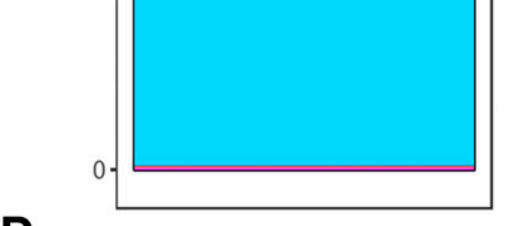

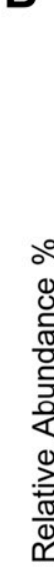

Achromobacter

Acinetobacter

Denitratisoma
- 
was diminished. Sequences were then processed using Quantitative Insights Into Microbial Ecology (QIIME) version 1.8.0 (Caporaso et al. 2010). De-multiplexing and quality filtering were performed using default parameters except that the minimum number of consecutive high quality base calls to include a read as a fraction of input read length was raised to 0.99 . Chimeric sequences were detected using the denovo method of USEARCH 6.1 (Edgar 2010) and then removed. Denovo operational taxonomic units (OTUs) were picked at $97 \%$ similarity and singlet OTUs were removed. OTUs having nonbacterial DNA were identified by performing a local BLAST search (Altschul et al. 1990) of their sequences against the nucleotide database. OTUs were removed if any of their highest scoring BLAST hits contained taxonomic IDs within the grapevine family Vitaceae, fungi or PhiX, or if they contained no hits to any bacteria. Taxonomic assignments to bacterial OTUs were made using the May 5th, 2013 version of the Greengenes reference database (DeSantis et al. 2006) using QIIME's default parameters. For statistical and graphical representation of the data, OTU tables were rarified to an even depth of 6,000 reads per samples. Samples with less than 6,000 reads were removed from the OTU table. The bacterial sequences can be found at NCBI under the accession number PRJNA361009.

Fungal rRNA gene sequencing. Illumina fungal rRNA ITS libraries were constructed as follows. One-hundred-microliter amplification reactions were performed in a MJ Research PTC200 thermal cycler (Bio-Rad Inc.) and contained $50 \mathrm{mM}$ Tris ( $\mathrm{pH}$ 8.3), BSA at $500 \mu \mathrm{g} \mathrm{ml} l^{-1}, 2.5 \mathrm{mM} \mathrm{MgCl}_{2}, 250 \mu \mathrm{M}$ of each deoxynucleotide triphosphate (dNTP), $400 \mathrm{nM}$ of each primer, $4 \mu \mathrm{l}$ of DNA template, and 2.5 units of JumpStart Taq DNA polymerase (Sigma-Aldrich). The PCR primers gITS7 (GTGARTCATCGAR TCTTTG) and ITS4-1 (TCCTCCGCTTATTGATATGC) targeted the ITS 2 region of the ribosomal rRNA gene operon, with the reverse primers including a 7-bp barcode (Ihrmark et al. 2012; White et al. 1990). Thermal cycling parameters were $94^{\circ} \mathrm{C}$ for $5 \mathrm{~min} ; 35$ cycles of $94^{\circ} \mathrm{C}$ for $20 \mathrm{~s}, 56^{\circ} \mathrm{C}$ for $20 \mathrm{~s}$, and $72^{\circ} \mathrm{C}$ for $30 \mathrm{~s}$, and followed by $72^{\circ} \mathrm{C}$ for $10 \mathrm{~min}$. PCR products were purified using a Qiagen QIAquick PCR purification kit (Qiagen) according to the manufacturer's instructions.

DNA sequencing was performed using an Illumina Miseq (Illumina, Inc.). Clusters were created using template concentrations 1.0 $\mathrm{pM}$ and PhiX at $65 \mathrm{~K} / \mathrm{mm}^{2}$. Raw read lengths were 301 bases. Raw sequences were processed using QIIME version 1.8.0 (Caporaso et al. 2010). De-multiplexing and quality filtering were performed using default parameters except that the minimum allowed Phred quality score was raised to Q30. Chimeric sequences were detected using the denovo method of USEARCH 6.1 (Edgar 2010) and then removed. Denovo OTUs were picked at $99 \%$ similarity and singlet OTUs were removed. OTUs having nonfungal DNA were identified by performing a local BLAST search (Altschul et al. 1990) of their sequences against the nucleotide database. OTUs were removed if any of their highest scoring BLAST hits contained taxonomic IDs within the grapevine family Vitaceae or PhiX, or if they contained no hits to any fungi. Taxonomic assignments to fungal OTUs were made

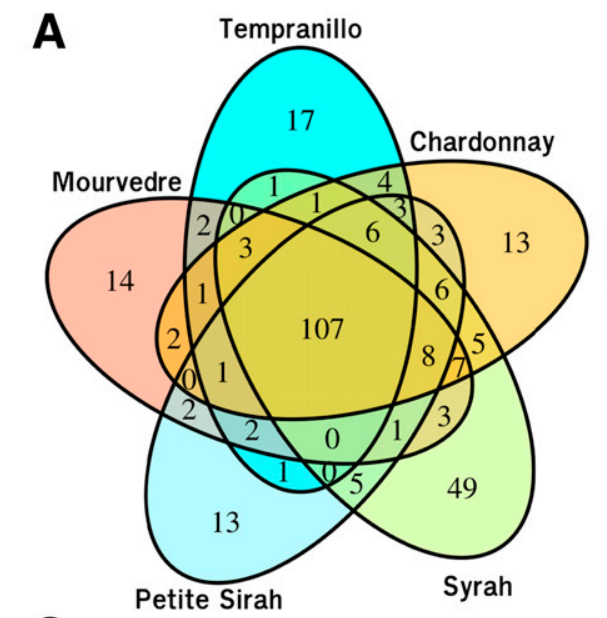

B
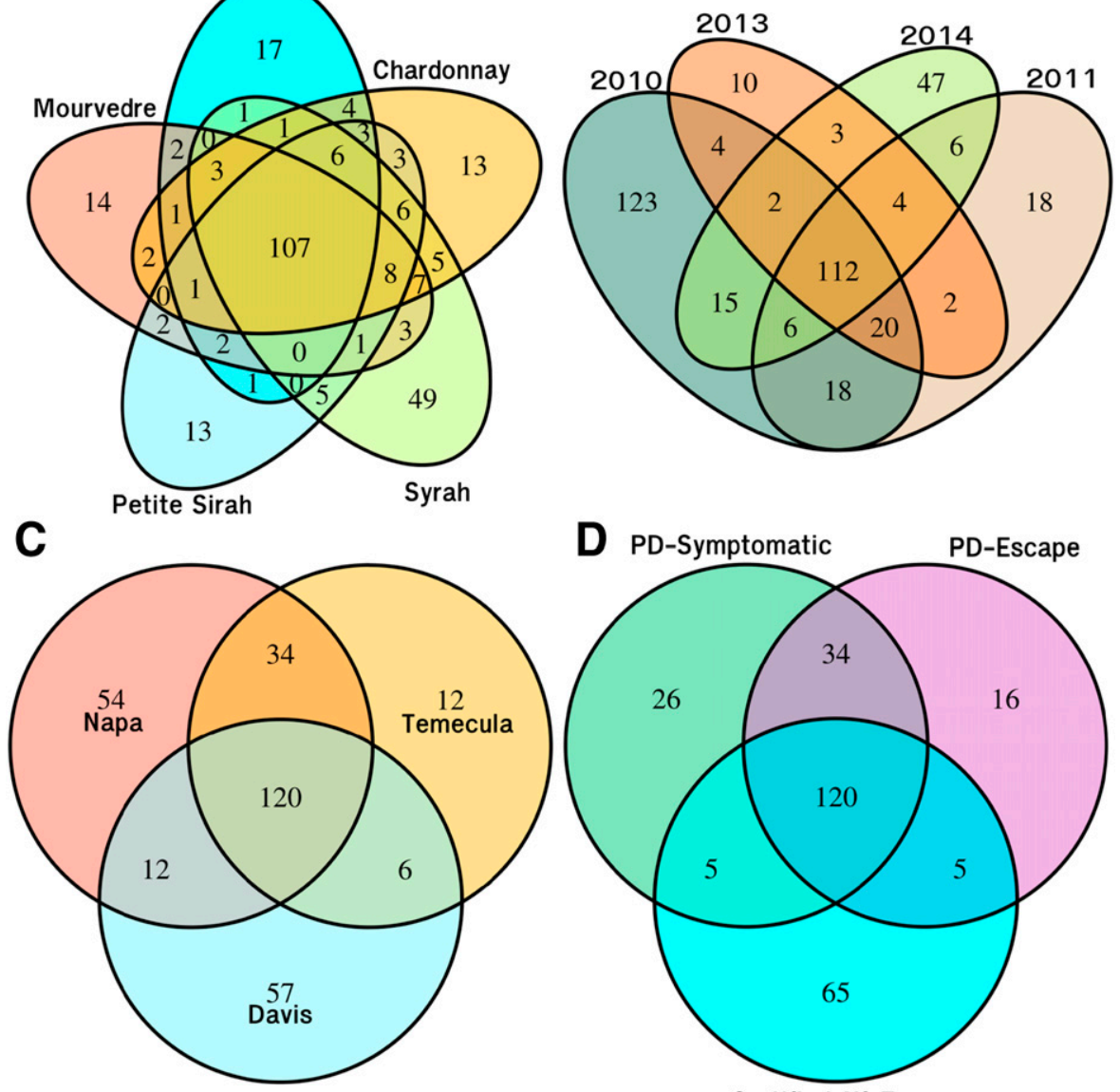

D PD-Symptomatic

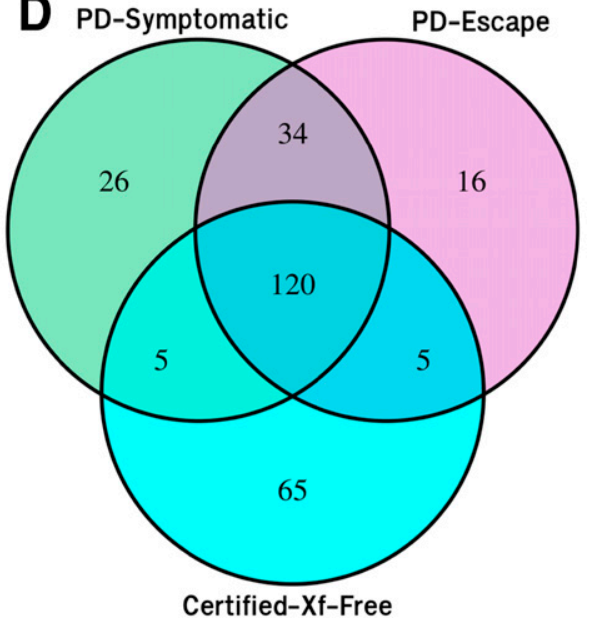

Fig. 3. Venn Diagrams depicting the number of shared and different operational taxonomic units based on four variables: A, grapevine cultivar ( $n=60)$; $\mathbf{B}$, sampling year $(n=72)$; $\mathbf{C}$, vineyard location $(n=72)$; and $\mathbf{D}$, grapevine condition $(n=72)$. 
with the RDP Classifier (Wang et al. 2007) using the July 2014 UNITE fungal database (Koljalg et al. 2005). BLASTN 2.4.0 was used to identify the top 50 genus level sequences that were unable to be identified through RDP database. Genus level names were adopted for each sequence if there was a $97 \%$ identity and had a cut-off E-value of E-120. The newly identified genera were added to the original OTU table obtained through QIIME. For fungal taxonomy barplots, OTU tables were rarefied to 1,000 reads per sample. Samples with less than 1,000 reads were removed from the dataset. The fungal sequences can be found at NCBI under the accession number PRJNA361126.

Microbiome data analyses. Using the rarified OTU tables from QIIME, R 3.4.0 (https://www.r-project.org/) was employed for the graphical and statistical analysis. The Phyloseq package 1.20.2 (McMurdie and Holmes 2013) and ggplot2 2.2.1 (Wickham 2009) were utilized for further parsing the OTU tables and graphical representations. Taxonomy plots for bacteria and fungi were generated from 72 and 34 samples, respectively, by pruning OTUs for only those representing at least $1 \%$ of the bacterial or fungal OTU table. Venn diagrams were also created with the $\mathrm{R}$ package VennDiagram (Chen and Boutros 2011) version 1.6.17 (https://cran.rstudio.com/ web/packages/VennDiagram/VennDiagram.pdf) and demonstrated the presence/absence of number of bacterial OTUs occurring in various metadata categories including cultivar (60 samples), sampling year (72 samples), vineyard location (72 samples) and grapevine condition (72 samples). Wilcoxon test corrected by false discovery rate (FDR) values were used to statistically compare $X$. fastidiosa abundance and incidence in PD-symptomatic versus PD-escape grapevine. Pearson correlation analyses from 67 samples (excluding FPS plant samples) between the numbers of $X$. fastidiosa sequencing reads and the relative abundance of the other bacterial taxa were performed using the $\mathrm{R}$ package Hmisc 4.0-3 (http:// biostat.mc.vanderbilt.edu/wiki/Main/Hmisc). FDR was used to adjust $P$ values. Hellinger distance matrix was calculated using 72 samples with QIIME (Caporaso et al. 2010) and used to create principal coordinates analysis (PCoA) plots. The Hellinger distance matrix was also used on all 72 samples to create the Canonical analysis of principal coordinates (CAP) plot using the Vegan package (https:// cran.r-project.org/web/packages/vegan/index.html). Statistics for the PCoA was carried out with an Adonis test. Adonis was run on Xylella and Pseudomonas abundances. Similarly, ANOVA like permutation test for constrained analysis was run to determine statistical significance between Xylella and Pseudomonas abundance among samples.

Chromosome primer walking. To obtain the sequences of a greater portion of the $16 \mathrm{~S}$ rRNA gene along with the internal transcribed spacer (ITS) region for selected OTUs, chromosome walking was conducted as follows. Samples that showed relative high abundance of the most abundant Pseudomonas OTU\#646559 and Achromobacter OTU\#558264 based on Illumina sequencing were selected. PCR was performed on the total DNA using a nested approach. The first PCR used primers targeting the small-subunit rRNA gene and the large-subunit rRNA gene: $530 \mathrm{~F}$ (GTGCCAGCM GCCGCGG) and 23SR (GGGTTBCCCCATTCRG). PCR products were diluted 1:99 and then subjected to sequence-selective PCRs where the reverse primer was 23SR (GGGTTBCCCCATTCRG) and the following sequence-selective forward primers were Achromobacter (TTTAACTACCGAGCTAGAG) and Pseudomonas (AACTGACTG ACTAGAGTAT). Amplification products were gel isolated and cloned as described previously (Bent et al. 2009), and the nucleotide sequences were obtained using ABI Cycle Sequencing (Applied Biosystems, Foster City, CA). For the Pseudomonas analyses, we analyzed 16 different samples and obtained bands of the predicted size from 14 samples. Six of these bands were cloned and sequenced, resulting in
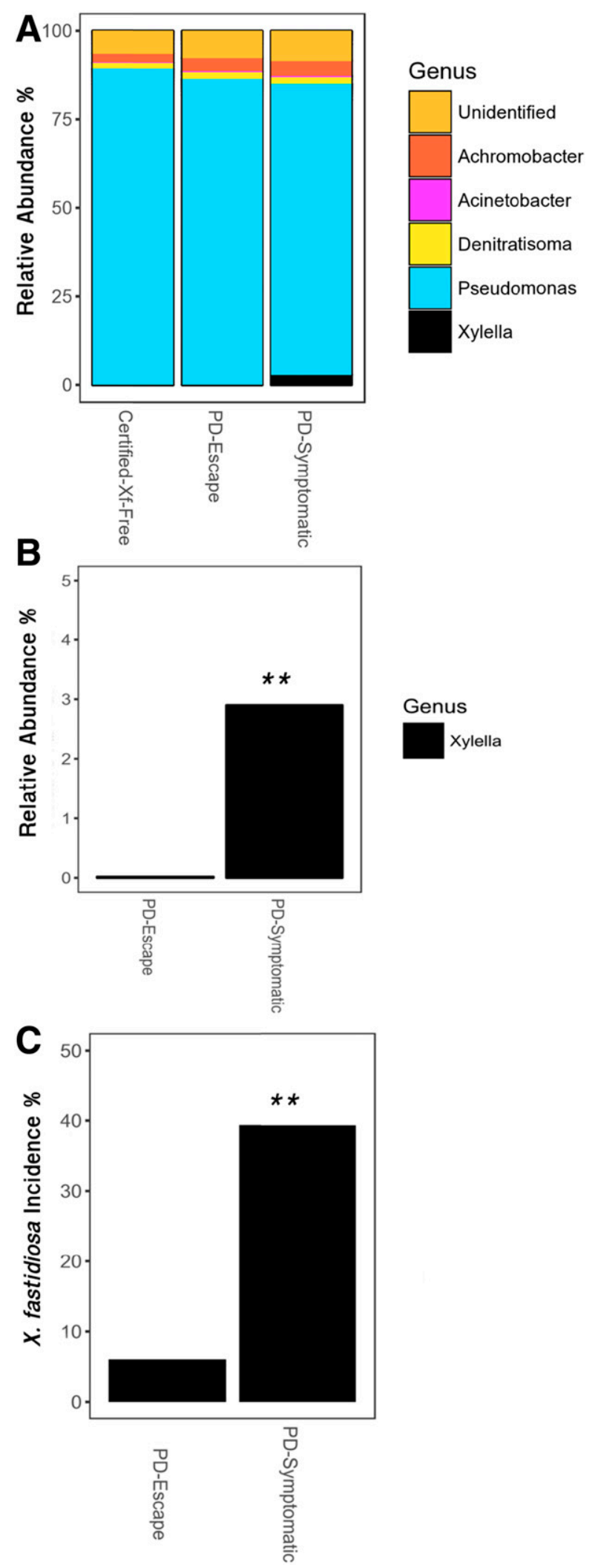

Fig. 4. A, Abundance of genus level taxa identified in certified Xylella fastidiosa-free, PD-escape and PD-symptomatic vines $(n=72)$. B, $X$. fastidiosa relative abundance (mean percent) in PD-escape and PD-symptomatic grapevines; ${ }^{* *}$ indicates a statistical significant difference $(P<0.01 ; n=67)$. C, $X$. fastidiosa incidence (percentage of vines where $X$. fastidiosa reads could be detected) in PD-symptomatic versus PD-escape; ** indicates a statistical significant difference $(P<0.01 ; n=67)$. 
eight sequences from three different samples that had $100 \%$ identity to the sequence of Illumina Pseudomonas OTU \#646549. These sequences were examined further by a phylogenetic tree analysis described below. For the Achromobacter analyses, we analyzed 16 different samples and obtained bands of the predicted size from 13 samples. Six of these bands were cloned and sequenced, resulting in four sequences from two different samples that had $100 \%$ identity to the sequence of Illumina Achromobacter OTU \#558264. The best match to all four of these sequences was Achromobacter xylosoxidans as determined using BLAST analyses.

Phylogenetic analysis. To better identify the species name of the most abundant Pseudomonas OTU\#646549, a multiloci phylogenetic tree was created. BLASTN was used to find homologous sequences in the Pseudomonas genome sequence database (Loper et al. 2012). The sequences averaged 1,524 base pairs in length and included 16S, ITS, and 23S loci. A total of 32 Pseudomonas sequences were aligned using ClustalW (Geneious v. 6.1.6; Biomatters Ltd.). The evolutionary history was inferred by using the maximum likelihood method based on the Tamura-Nei model (Tamura and Nei 1993). Initial trees for the heuristic search were obtained automatically by applying neighbor-join and BioNJ algorithms to a matrix of pairwise distances estimated using the maximum composite likelihood approach, and then selecting the topology with superior log likelihood value. All positions containing gaps and missing data were eliminated. There was a total of 1,408 positions in the final dataset. Bootstrap values were inferred using 1,000 replicates. Evolutionary analyses were conducted in MEGA7 (Kumar et al. 2016).

\section{RESULTS}

The grapevine endophytic microbiome was characterized from lignified shoot samples collected from ten vineyards across California, including five commercial vineyards in the Temecula Valley, four commercial vineyards in the Napa Valley and one vineyard from the Foundation Plant Services at UC Davis. A total of 60 and $1.1 \%$ of the total number of reads were of grapevine origin for bacteria and fungi, respectively. After removing plants reads, we obtained 2,209,462 and 462,294 total high quality reads for the bacterial and fungal data sets. After processing the rarefied data, 918 and 4,437 bacterial and fungal OTUs were identified, respectively.

Community analysis was performed with only OTUs representing greater than $1 \%$ of the data and transformed to relative abundance for taxonomy plots. For fungal taxonomy, barplots (Fig. 1; Supplementary Fig. S2) were constructed with 34 samples because 39 samples with less than 1,000 reads were removed from the dataset. Our results showed that fungal communities were predominately comprised of phyla belonging to the Ascomycota (89.2\%), which was mostly composed of four classes including Dothideomycetes (79.3\%), Sordariomycetes $(6.4 \%)$, Pezizomycetes $(2.2 \%)$, and Eurotiomycetes $(1.3 \%)$. Within the Dothidiomycetes, the Pleosporales $(46.5 \%)$ was the most abundant order and was comprised of four genera including one unassigned genera Alternaria, Sporomiella, and Embellisia. The Dothidiomycetes also included three additional orders Capnodiales (24.5\%), Dothideales (6\%), and Botryosphaeriales (2.1\%) and were represented predominantly by Cladosporium, Aureobasidium, and Diplodia, respectively. The Sordariomycetes was represented predominantly by the order Sordariales $(6.4 \%)$ with one genus, Chaetomium. The Eurotiomycetes was represented predominantly by the order Eurotiales (1.3\%) comprised of mainly Aspergillus. Pezizomycetes was represented by the single order Pezizales and one unassigned genus and the genus Ascorhizoctonia. Organisms belonging to the phylum Basidiomycota represented only $1.9 \%$ and were mostly composed of organisms belonging to the class Tremellomycetes, order Filobasidiales and genus Cryptococcus. Interestingly, $46.9 \%$ of the remaining fungi could not be assigned at the genus level indicating they are likely undescribed species. Because only 34 of the 73 initial samples could be used in our analysis after rarefaction, we did not further analyze $X$. fastidiosa associations in the context of the fungal community.

In comparison, the bacterial dataset was more robust following rarefaction method allowing us to use 72 of the 73 samples. Our results showed that the bacterial communities (Fig. 2) were predominately comprised of organisms belonging to the phylum Proteobacteria $(99.5 \%)$ and especially two classes, Gammaproteobacteria $(89.3 \%)$ and Betaproteobacteria (10.2\%). Among the Gammaproteobacteria the two dominant orders were Pseudomonadales $(86.8 \%)$ and Xanthomonadales (1.7\%) and were predominantly represented by Pseudomonas and Xylella, respectively. Among the Betaproteobacteria the two dominant orders were Burkholderiales (3.8\%) and Rhodocyclales $(1.9 \%)$ and were predominantly represented by the genera Achromobacter and Denitratisoma, respectively. We also identified additional phyla but at a very low abundance. For example, Bacteroidetes $(0.4 \%)$ was the second most abundant phylum followed by Verrucomicrobia $(0.1 \%)$.

Venn diagrams were generated to assess the common and different bacterial OTUs among four variables (sampling year, vineyard location, vine condition, and grapevine cultivar) (Fig. 3). OTUs had to occur in a minimum of $10 \%$ of the vines in any group to be included. Among five grape cultivars with at least 10 samples (Table 1), we identified 107 shared OTUs. Syrah had the most unique OTUs ( $n=47)$ followed by Chardonnay $(n=38)$, Tempranillo $(n=14)$, Mourvedre $(n=13)$, and Petite Sirah $(n=11)$. Among the 72 samples collected from all four years, 112 OTUs were shared between sampling dates. The year 2010 had the most unique OTUs $(n=$ $123)$, followed by $2014(n=47), 2011(n=18)$, and $2013(n=10)$.

TABLE 2

Bacterial operational taxonomic units (OTUs) correlating negatively and positively with Xylella

\begin{tabular}{llcccc}
\hline OTUs & $P$ & FDR corrected & $r^{\text {a }}$ & Number of OTUs & Relative abundance (\%) $^{\text {b }}$ \\
\hline Pseudomonas & 0.000 & 0.00 & -0.84 & 84 & 82.2 \\
\hline Achromobacter & 0.043 & 0.043 & -0.25 & 12 & 3.89 \\
\hline Bacillus & 0.009 & 0.013 & 0.32 & 9 & 0.01 \\
\hline Caulobacter & 0.0433 & 0.043 & 0.37 & 1 & $1 \mathrm{e}-03$ \\
\hline Pediococcus & $2.8 \mathrm{E}-5$ & $5.6 \mathrm{E}-5$ & 0.49 & 1 & $5 \mathrm{e}-04$ \\
\hline Dialister & 0.000 & 0.000 & 0.81 & 1 & $2 \mathrm{e}-04$ \\
\hline
\end{tabular}

a Pearson correlation analyses were performed between the numbers of Xylella fastidiosa sequencing reads and the relative abundance of other bacterial taxa. Standard $(P)$ and false discovery rate (FDR) corrected probability values are presented along with the correlation coefficient $(r)$. $n=67$.

b Total number of OTUs with the same genus and a significant $P$ value. 
In addition, 120 OTUs were shared between sampling locations. FPS samples from Davis had 57 unique OTUs, Napa had 54 and Temecula had 12 unique OTUS. Similarly, 120 OTUs were shared between vine conditions with 65, 16, and 26 unique OTUs for the certified $X$. fastidiosa-free plants, escape, and symptomatic grapevines, respectively. Ninety-eight OTUs (Supplementary Table S1) were shared among all the inner circles of the four Venn diagrams $($ condition $=154$; year $=112$, location $=120$; variety $=107$ ).
Bacterial community composition was impacted by the condition of the vine (Fig. 4A). Statistical analyses showed that $X$. fastidiosa was found both in significantly higher abundance $(P<0.01)$ (Fig. 4B) and at a significantly higher incidence $(P<0.01)$ (Fig. 4C) in PD-symptomatic than PD-escape grapevines. Symptom severity on the scale of a whole plant directly correlates with an increase in Xylella titer and the reason that $X$. fastidiosa incidence is not reported at $100 \%$ in symptomatic vines is likely due to the heterogeneous distribution of $X$. fastidiosa within the xylem architecture

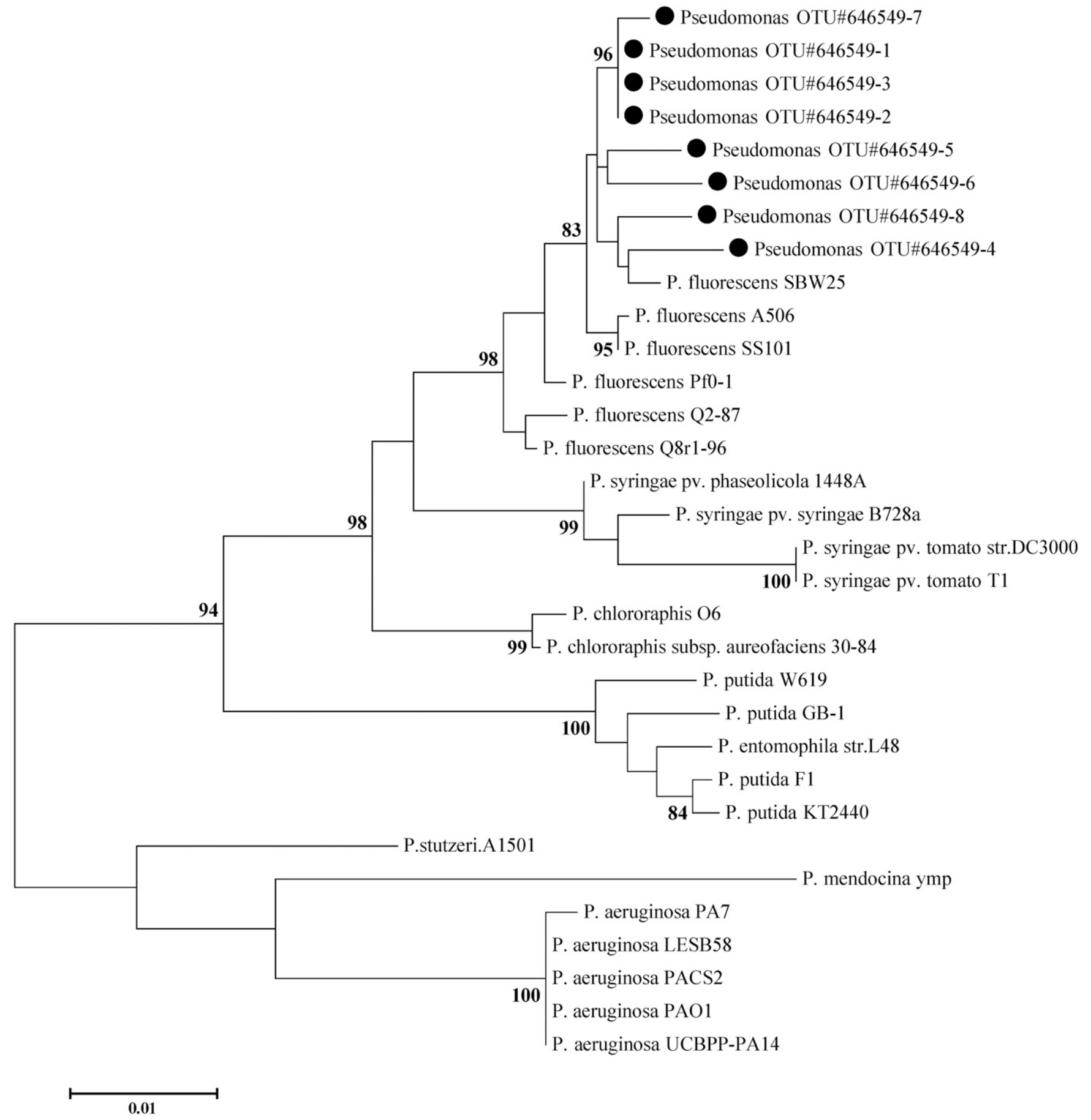

Fig. 5. Molecular phylogenetic analysis by maximum likelihood method. The tree with the highest log likelihood (-4322.4984) is shown. Bootstrap values were inferred using 1,000 replicates. The tree is drawn to scale, with branch lengths measured in the number of substitutions per site. The eight Pseudomonas sequences that displayed 100\% match with the dominant operational taxonomic unit (OTU) \#646549 identified from the grape cane endosphere are labeled with a full circle. 
of grapes (Clifford et al. 2013). In addition, four bacterial taxa with very low abundance correlated positively with Xylella including Bacillus, Pediococcus, Caulobacter, and Dialister (Table 2). Most notably, Pseudomonas and Achromobacter, two of the predominant phylotypes in the cane endosphere (Fig. 2), showed significant negative correlations with Xylella (Table 2). Because of the potential application of those bacteria as biological control agents for management of PD, these taxa were further identified to the species level. Chromosomal walking was used to obtain a greater portion of Pseudomonas and Achromobacter 16S rRNA gene sequence, along with their rRNA ITS sequence, producing sequences that were approximately $1,500 \mathrm{bp}$ in length. From this we determined that the species designations for these taxa were $P$. fluorescens or $P$. chlororaphis and A. xylosoxidans. Because we could not assign with confidence a species name to the Pseudomonas OTU \#646549 (i.e., the most abundant Pseudomonas OTU) using nucleotide BLAST search, we used a maximum likelihood analysis to resolve species identity (Fig. 5). Results showed that our Pseudomonas sequences clustered with $P$. fluorescens with strong bootstrap support (98\%).

Beta-diversity plots using a Hellinger distance matrix showed evidence of compositional divergence when looking at abundance of Xylella and Pseudomonas counts (Fig. 6). The clustering of bacterial communities appeared to be primarily driven by the abundance of Xylella and Pseudomonas. Adonis test revealed a significant $P$ value and correlation coefficient for both Xylella $\left(P<0.001, R^{2}=0.34\right)$ and Pseudomonas $\left(P<0.001, R^{2}=0.28\right)$ beta-diversity metrics. A canonical correspondence of principal coordinate analysis was run to better identify the factors contributing to the variance in the dataset (Fig. 7). Results reiterate that abundance of Xylella and abundance of Pseudomonas carry

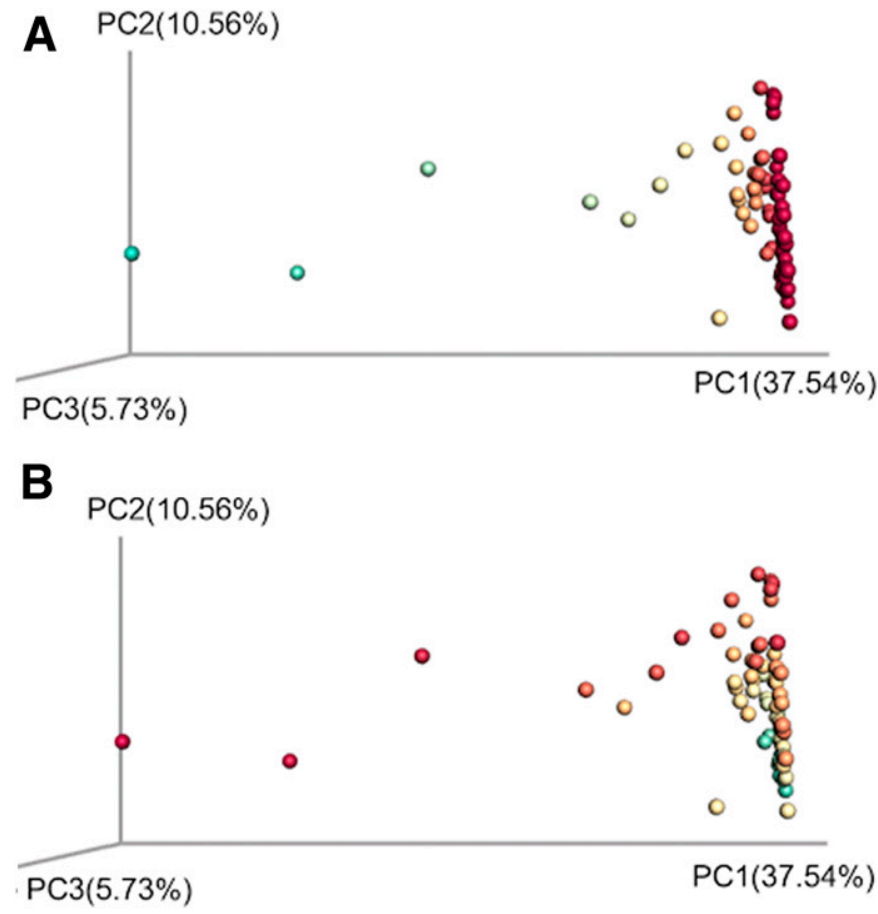

Fig. 6. Principal coordinates analysis (PCoA) plots based on Hellinger distance matrix plotted with the first three dimensions. Comparison of bacterial communities by A, abundance of Xylella fastidiosa and $\mathbf{B}$, abundance of Pseudomonas. Points represent individual samples in the data set. Red indicates lower abundance and blue indicates higher abundance. Adonis test revealed a significant $P$ value and coefficient correlation for abundance of both $P$ seudomonas $\left(P<0.001 ; R^{2}=0.28\right)$ and Xylella $\left(P<0.001, R^{2}=0.34\right)$. the heaviest weight on the data set with these two forces driving the data in divergent directions $(P<0.001)$. The data points in Figure 7 are colored by condition but the data were analyzed by $X$. fastidiosa abundance. Beta-diversity using Hellinger distance matrix did not show any compositional divergence belonging to any other metadata variable (i.e., condition of vine, sampling time, and vineyard location; data not shown).

\section{DISCUSSION}

Grapevine has become a model system for investigations of microbial communities associated with agricultural crops and different grape plant organs support distinct microbial communities. Berry flora has been a major focal point (Bokulich et al. 2014; Zarraonaindia et al. 2015) because of the interest in indigenous microbes as contributors of the regional organoleptic properties (i.e., terroir). Zarraonaindia et al. (2015) determined that above-ground grape bacterial communities are significantly different than the cognate belowground soil bacterial communities. However, specific above-ground (leaves, berries, and flowers) communities were more similar to below ground soil communities than they were to each other. Here we focused our study on the endosphere of the above-ground cane tissue. Canes are lignified shoots that bear leaves and grape clusters. Canes are seasonal, annually produced vine tissues that emerge from buds in the spring and are pruned off in the fall after harvest. Our data indicated that the grapevine cane endosphere hosts a bacterial community structure with species of similar relative abundances to communities described for other annually produced aerial plant parts (i.e., grape flowers berries and leaves) with a high abundance of Proteobacteria and a low incidence of Firmicutes, Acidobacteria, and Bacteriodetes (Zarraonaindia et al. 2015). Faist et al. (2016) also supported these results although they found a higher abundance of Firmicutes, Actinobacteria, and Bacteriodetes in canes likely due to the difference with sampling location and design, grapevine cultivar and

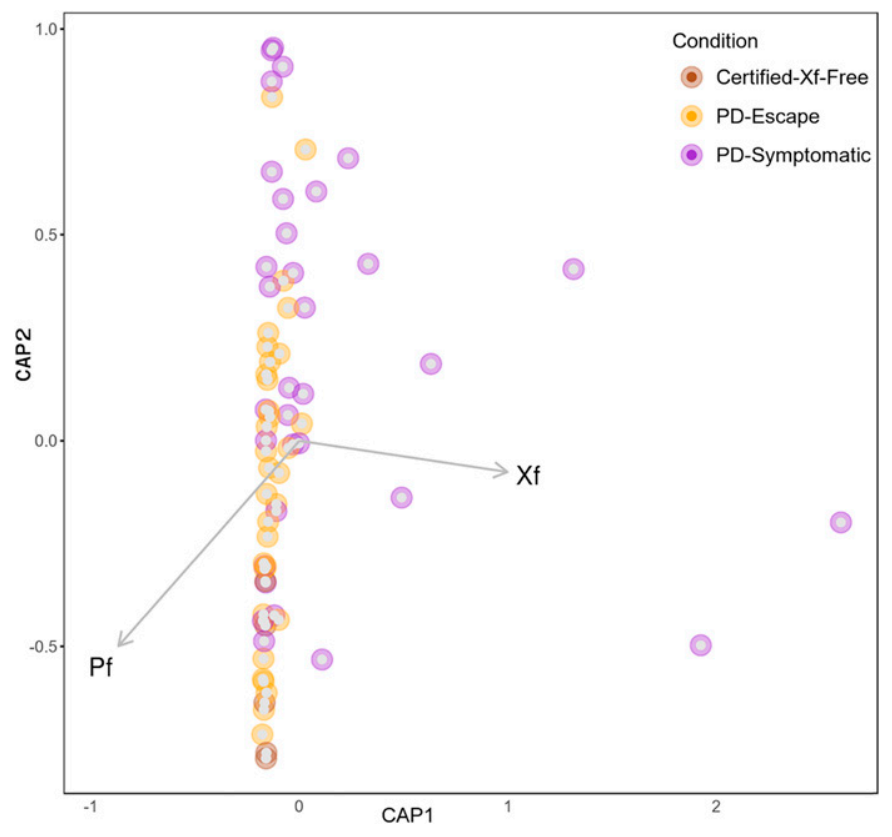

Fig. 7. Bacterial community variation represented by canonical analysis of principal coordinates (Hellinger distance matrix) plotted on the first two dimensions. Top contributors of community variation are represented by arrows, $\mathrm{Pf}=P$ seudomonas fluorescens; $\mathrm{Xf}=$ Xylella fastidiosa. Arrows are in divergent directions $(P<0.001)$. Dots are colored by condition but the data were analyzed by $X$. fastidiosa abundance. 
rootstock and environmental conditions. In addition, we found that Verrucomicrobia was represented in the cane endosphere, albeit low abundance. Zarraonaindia et al. (2015) showed that Verrucomicrobia were absent in leaves, berries, or flowers but were abundant in the soil, grape rhizosphere, and root endosphere. This suggests that the Verrucomicrobia found in the internal cane endosphere is likely derived from the soil or rhizosphere.

Fungi are an important segment of the plant microbiome and a key determinant to plant health (Pieterse et al. 2014; Shoresh et al. 2010). Deciphering their biological functions could lead to new strategies for disease control and integrated pest management. For example, fungi produce a diversity of structurally distinctive compounds with antimicrobial properties (Aldrich et al. 2015; Porras-Alfaro and Bayman 2011). Culture-independent grape microbiome studies have primarily been centered on bacterial community composition and to our knowledge, our study is the initial report of culture-independent analyses of the fungal communities associated with grapevine cane endosphere. There are other cultureindependent studies that focused on fungal communities on preharvest phyllosphere (Perazzolli et al. 2014; Pinto et al. 2014) and postharvest grape berries just before fermentation (Bokulich et al. 2014). Our data showed that overall the fungal community composition was more diverse than the bacterial community composition in terms of total number of OTUs. Several taxa (Cryptococcus, Alternaria, Sporomiella, and Aureobasidium) inhabiting the grape cane endosphere were also previously reported in the grape phyllosphere (Perazzolli et al. 2014; Pinto et al. 2014). In addition, we found that several fungal taxonomic groups remained unclassified suggesting that the conditions of the plant vascular system (i.e., low oxygen, negative pressure, and nutrient availability) have selected for unique taxa that have adapted to this particular niche that are not well represented in publicly available databases.

At the genus and species level, the cane endosphere bacterial community was composed primarily of Pseudomonas, which aligns with previous results from Faist et al. (2016). We determined that $P$. fluorescens was the main species inhabiting the grapevine cane endosphere and we also found that it was in significantly higher abundance in PD-escape vines versus PD-symptomatic vines. In fact, the clustering of bacterial communities appeared to be driven by the incidence of these $P$. fluorescens and X. fastidiosa in the endosphere. This suggests that perhaps $P$. fluorescens has the ability to mitigate the establishment of $X$. fastidiosa and confer the host escape phenotype. $P$. fluorescens is commonly found in association with the rhizosphere, phyllosphere and endosphere of other plant species. Moreover, it is a known biological control agent in many pathosystems, but can also protect against abiotic stresses and stimulate plant growth (Bardas et al. 2009; Lugtenberg and Kamilova 2009; Maksimov et al. 2011; Olanya et al. 2016; Samavat et al. 2014; Shen et al. 2013; Srinivasan et al. 2009). This bacterium produces a diverse array of secondary metabolites that have antimicrobial properties, such as phenazines, lipopeptides, hydrogen cyanide and 2,4-diacetylphloroglucinol and antibiosis is described as a mechanism underlying how this bacterium imparts broad spectrum disease control (Arseneault et al. 2016; Loper et al. 2012; Michelsen et al. 2015; Rezzonico et al. 2007). In addition, P. fluorescens is a welldescribed plant growth promoting rhizobacteria. It has been shown to actively colonize the plant rhizosphere and the root endosphere and activate ISR (Kloepper et al. 1992) that can confer increased immunity against a broad range of plant pests and diseases in some plant species (Bolwerk et al. 2003; Cabanas et al. 2014; Maksimov et al. 2011; Pieterse et al. 1996; Pieterse et al. 2014). In grapevine, $P$. fluorescens can become established in the grape rhizosphere and suppress the growth of the pathogenic bacterium Agrobacterium spp., the causal agent of crown gall (Khmel et al. 1998). Moreover, it can actively colonize the root endosphere and trigger a systemic induced response that provide enhanced resistance against the leaf and berry pathogen Botrytis cinerea, the causal agent of gray mold (Aziz et al. 2016; Gruau et al. 2015). Future biological and functional genomic studies will allow us to decipher the molecular basis underlying $P$. fluorescens putative antagonistic or ISR-inducing mechanism of action against $X$. fastidiosa in planta.

Achromobacter xylosoxidans was also an abundant member of the microbial community occupying the grape cane endosphere that correlated negatively with $X$. fastidiosa suggesting that this bacterial taxon could also play a role in the disease escape phenotype. A. xylosoxidans is a known plant growth promoting rhizobacteria (Forchetti et al. 2010; Mayak et al. 2004) and a biological control agent of many plant pathogens (de Boer et al. 2015; Triki et al. 2012). A. xylosoxidans is commonly found in aqueous environments and soils. This organism can metabolize nitrate and glyphosate (Ermakova et al. 2010; Felgate et al. 2012), which are commonly used in grape production systems as part of fertilization regimes and weed management, respectively. We speculate that this bacterium has been selected for in vineyard soils because of these standard viticultural practices and may have been introduced through the irrigation water.

Plants can acquire microorganisms from soil and those selected microbes can move to the rhizosphere and root endosphere to fulfill specific biological functions (Berendsen et al. 2012). It was also proposed that organisms that inhabit the vascular system originate in part from the roots through the lumen of xylem vessels via the plant evapotranspiration stream (Compant et al. 2010). Other entry points to the plant vascular system may also include insect feeding (Lopez-Fernandez et al. 2017) wounding (Munkvold and Marois 1993) and perhaps plant natural openings (i.e., stomata). The origin of the endosphere-associated A. xylosoxidans and P. fluorescens or any of the other phylotypes, aside from $X$. fastidiosa, is presently unknown and understanding how these microbes are introduced into the endosphere will rely on future, detailed niche partitioning experiments. In addition, collecting more information on microbial community dynamics during the grapevine annual phenological cycle with relation to pre- and post- $X$. fastidiosa infection events following sharpshooter feeding, pathogen colonization and PD symptoms development may provide novel solutions to PD management.

\section{ACKNOWLEDGMENTS}

We thank the California Department of Food and Agriculture Pierce's Disease and Glassy Winged Sharpshooter Board for supporting this research (awarded to P. Rolshausen). We would also like to thank B. Kirkpatrick for assistance in identifying vineyards with disease escape vines. We also thank Foundation Plant Services (UC Davis) for supplying foundation plant material for this study.

\section{LITERATURE CITED}

Aldrich, T. J., Rolshausen, P. E., Roper, M. C., Reader, J. M., Steinhaus, M. J., Rapicavoli, J., Vosburg, D. A., and Maloney, K. N. 2015. Radicinin from Cochliobolus sp. inhibits Xylella fastidiosa, the causal agent of Pierce's disease of grapevine. Phytochem. Amst. 116:130-137.

Almeida, R. P. P., and Nunney, L. 2015. How do plant diseases caused by Xylella fastidiosa emerge? Plant Dis. 99:1457-1467.

Alston, J. M., Fuller, K. B., Kaplan, J. D., and Tumber, K. P. 2013. Economic consequences of Pierce's disease and related policy in the California Winegrape Industry. J. Agric. Resour. Econ. 38:269-297.

Altschul, S. F., Gish, W., Miller, W., Myers, E. W., and Lipman, D. J. 1990. Basic local alignment search tool. J. Mol. Biol. 215:403-410.

Arseneault, T., Goyer, C., and Filion, M. 2016. Biocontrol of potato common scab is associated with high Pseudomonas fluorescens LBUM223 
populations and phenazine-1-carboxylic acid biosynthetic transcript accumulation in the potato geocaulosphere. Phytopathology 106:963-970.

Aziz, A., Verhagen, B., Magnin-Robert, M., Couderchet, M., Clement, C., Jeandet, P., and Trotel-Aziz, P. 2016. Effectiveness of beneficial bacteria to promote systemic resistance of grapevine to gray mold as related to phytoalexin production in vineyards. Plant Soil 405:141-153.

Bais, H. P., Weir, T. L., Perry, L. G., Gilroy, S., and Vivanco, J. M. 2006. The role of root exudates in rhizosphere interactions with plants and other organisms. Annu. Rev. Plant Biol. 57:233-266.

Bardas, G. A., Lagopodi, A. L., Kadoglidou, K., and Tzavella-Klonari, K. 2009. Biological control of three Colletotrichum lindemuthianum races using Pseudomonas chlororaphis PCL1391 and Pseudomonas fluorescens WCS365. Biol. Control 49:139-145.

Bent, E., Loffredo, A., Yang, J.-I., McKenry, M. V., Becker, J. O., and Borneman, J. 2009. Investigations into peach seedling stunting caused by a replant soil. FEMS Microbiol. Ecol. 68:192-200.

Berendsen, R. L., Pieterse, C. M. J., and Bakker, P. A. H. M. 2012. The rhizosphere microbiome and plant health. Trends Plant Sci. 17:478-486.

Blua, M. J., Phillips, P. A., and Redak, R. A. 1999. A new sharpshooter threatens both crops and ornamentals. Calif. Agric. 53:22-25.

Bokulich, N. A., Thorngate, J. H., Richardson, P. M., and Mills, D. A. 2014. Microbial biogeography of wine grapes is conditioned by cultivar, vintage, and climate. Proc. Natl. Acad. Sci. USA 111:E139-E148.

Bolwerk, A., Lagopodi, A. L., Wijfjes, A. H. M., Lamers, G. E. M., ChinA-Woeng, T. F. C., Lugtenberg, B. J. J., and Bloemberg, G. V. 2003. Interactions in the tomato rhizosphere of two Pseudomonas biocontrol strains with the phytopathogenic fungus Fusarium oxysporum f. sp. radicis-lycopersici. Mol. Plant-Microbe Interact. 16:983-993.

Busby, P. E., Ridout, M., and Newcombe, G. 2016. Fungal endophytes: Modifiers of plant disease. Plant Mol. Biol. 90:645-655.

Cabanas, C. G. L., Schiliro, E., Valverde-Corredor, A., and Mercado-Blanco, J. 2014. The biocontrol endophytic bacterium Pseudomonas fluorescens PICF7 induces systemic defense responses in aerial tissues upon colonization of olive roots. Front. Microbiol. 5:427.

Campisano, A., Pancher, M., Puopolo, G., Puddu, A., Lopez-Fernandez, S., Biagini, B., Yousaf, S., and Pertot, I. 2015. Diversity in endophyte populations reveals functional and taxonomic diversity between wild and domesticated grapevines. Am. J. Enol. Vitic. 66:12-21.

Caporaso, J. G., Kuczynski, J., Stombaugh, J., Bittinger, K., Bushman, F. D., Costello, E. K., Fierer, N., Pena, A. G., Goodrich, J. K., Gordon, J. I., Huttley, G. A., Kelley, S. T., Knights, D., Koenig, J. E., Ley, R. E., Lozupone, C. A., McDonald, D., Muegge, B. D., Pirrung, M., Reeder, J., Sevinsky, J. R., Turnbaugh, P. J., Walters, W. A., Widmann, J., Yatsunenko, T., Zaneveld, J., and Knight, R. 2010. QIIME allows analysis of high-throughput community sequencing data. Nat. Methods 7:335-336.

Chen, H., and Boutros, P. C. 2011. VennDiagram: A package for the generation of highly-customizable Venn and Euler diagrams in R. BMC Bioinformatics 12:35.

Clifford, J. C., Rapicavoli, J. N., and Roper, M. C. 2013. A rhamnose-rich O-antigen mediates adhesion, virulence, and host colonization for the xylemlimited phytopathogen Xylella fastidiosa. Mol. Plant-Microbe Interact. 26: 676-685.

Compant, S., Clement, C., and Sessitsch, A. 2010. Plant growth-promoting bacteria in the rhizo- and endosphere of plants: Their role, colonization, mechanisms involved and prospects for utilization. Soil Biol. Biochem. 42:669-678

Compant, S., Mitter, B., Colli-Mull, J. G., Gangl, H., and Sessitsch, A. 2011. Endophytes of grapevine flowers, berries, and seeds: Identification of cultivable bacteria, comparison with other plant parts, and visualization of niches of colonization. Microbiol. Ecol. 62:188-197.

Darjean-Jones, D. 2004. Chemical and Biological Control Strategies for Management of Xylella fastidiosa, Causal Agent of Pierce's Disease of Grapevine. University of California, Davis.

de Boer, W., Hundscheid, M. P., Klein Gunnewiek, P. J., de Ridder-Duine, A. S., Thion, C., van Veen, J. A., and van der Wal, A. 2015. Antifungal rhizosphere bacteria can increase as response to the presence of saprotrophic fungi. PLoS One 10:e0137988.

DeSantis, T. Z., Hugenholtz, P., Larsen, N., Rojas, M., Brodie, E. L., Keller, K., Huber, T., Dalevi, D., Hu, P., and Andersen, G. L. 2006. Greengenes, a chimera-checked 16S rRNA gene database and workbench compatible with ARB. Appl. Environ. Microbiol. 72:5069-5072.

Doyle, J. J., and Doyle, J. L. 1987. Rapid DNA isolation procedure for small quantities of fresh leaf tissue. Phytochem. Bull. 19:11-15.

Edgar, R. C. 2010. Search and clustering orders of magnitude faster than BLAST. Bioinformatics 26:2460-2461.
Ermakova, I. T., Kiseleva, N. I., Shushkova, T., Zharikov, M., Zharikov, G. A., and Leontievsky, A. A. 2010. Bioremediation of glyphosate-contaminated soils. Appl. Microbiol. Biotechnol. 88:585-594.

Faist, H., Keller, A., Hentschel, U., and Deeken, R. 2016. Grapevine (Vitis vinifera) crown galls host distinct microbiota. Appl. Environ. Microbiol. 82: 5542-5552.

Felgate, H., Giannopoulos, G., Sullivan, M. J., Gates, A. J., Clarke, T. A., Baggs, E., Rowley, G., and Richardson, D. J. 2012. The impact of copper, nitrate and carbon status on the emission of nitrous oxide by two species of bacteria with biochemically distinct denitrification pathways. Environ. Microbiol. 14: 1788-1800.

Forchetti, G., Masciarelli, O., Izaguirre, M. J., Alemano, S., Alvarez, D., and Abdala, G. 2010. Endophytic bacteria improve seedling growth of sunflower under water stress, produce salicylic acid, and inhibit growth of pathogenic fungi. Curr. Microbiol. 61:485-493.

Gruau, C., Trotel-Aziz, P., Villaume, S., Rabenoelina, F., Clement, C., Baillieul, F., and Aziz, A. 2015. Pseudomonas fluorescens PTA-CT2 triggers local and systemic immune response against Botrytis cinerea in grapevine. Mol. PlantMicrobe Interact. 28:1117-1129.

Hopkins, D. L., and Purcell, A. H. 2002. Xylella fastidiosa: Cause of Pierce's disease of grapevine and other emergent diseases. Plant Dis. 86:1056-1066.

Ihrmark, K., Bodeker, I. T., Cruz-Martinez, K., Friberg, H., Kubartova, A., Schenck, J., Strid, Y., Stenlid, J., Brandstrom-Durling, M., Clemmensen, K. E., and Lindahl, B. D. 2012. New primers to amplify the fungal ITS2 region evaluation by 454-sequencing of artificial and natural communities. FEMS Microbiol. Ecol. 82:666-677.

Khmel, I. A., Sorokina, T. A., Lemanova, N. B., Lipasova, V. A., Metlitski, O. Z., Burdeinaya, T. V., and Chernin, L. S. 1998. Biological control of crown gall in grapevine and raspberry by two Pseudomonas spp. with a wide spectrum of antagonistic activity. Biocontrol Sci. Technol. 8:45-57.

Kloepper, J. W., Tuzun, S., and Kuc, J. A. 1992. Proposed definitions related to induced disease resistance. Biocontrol Sci. Technol. 2:349-351.

Koljalg, U., Larsson, K.-H., Abarenkov, K., Nilsson, R. H., Alexander, I. J., Eberhardt, U., Erland, S., Hoiland, K., Kjoller, R., Larsson, E., Pennanen, T., Sen, R., Taylor, A. F. S., Tedersoo, L., Vralstad, T., Ursing, B. M., and Ursing, B. M. 2005. UNITE: A database providing web-based methods for the molecular identification of ectomycorrhizal fungi. New Phytol. 166:1063-1068.

Kumar, S., Stecher, G., and Tamura, K. 2016. MEGA7: Molecular evolutionary genetics analysis version 7.0 for bigger datasets. Mol. Biol. Evol. 33: $1870-1874$.

Loper, J. E., Hassan, K. A., Mavrodi, D. V., Davis, E. W., II, Lim, C. K., Shaffer, B. T., Elbourne, L. D. H., Stockwell, V. O., Hartney, S. L., Breakwell, K., Henkels, M. D., Tetu, S. G., Rangel, L. I., Kidarsa, T. A., Wilson, N. L., de Mortel, J. E. v., Song, C., Blumhagen, R., Radune, D., Hostetler, J. B., Brinkac, L. M., Durkin, A. S., Kluepfel, D. A., Wechter, W. P., Anderson, A. J., Kim, Y. C., Pierson, L. S., III, Pierson, E. A., Lindow, S. E., Kobayashi, D. Y., Raaijmakers, J. M., Weller, D. M., Thomashow, L. S., Allen, A. E., and Paulsen, I. T. 2012. Comparative genomics of plant-associated Pseudomonas spp.: Insights into diversity and inheritance of traits involved in multitrophic interactions. PLoS Genet. 8:e1002784.

Lopez-Fernandez, S., Mazzoni, V., Pedrazzoli, F., Pertot, H., and Campisano, A. 2017. A phloem-feeding insect transfers bacterial endophytic communities between grapevine plants. Front. Microbiol. 8:834.

Lugtenberg, B., and Kamilova, F. 2009. Plant-growth-promoting rhizobacteria. Annu. Rev. Microbiol. 63:541-556.

Maksimov, I. V., Abizgil'dina, R. R., and Pusenkova, L. I. 2011. Plant growth promoting rhizobacteria as alternative to chemical crop protectors from pathogens. Appl. Biochem. Microbiol. 47:333-345.

Martins, G., Lauga, B., Miot-Sertier, C., Mercier, A., Lonvaud, A., Soulas, M. L., Soulas, G., and Masneuf-Pomarede, I. 2013. Characterization of epiphytic bacterial communities from grapes, leaves, bark and soil of grapevine plants grown, and their relations. PLoS One 8:e73013.

Mayak, S., Tirosh, T., and Glick, B. R. 2004. Plant growth-promoting bacteria confer resistance in tomato plants to salt stress. Plant Physiol. Biochem. Paris 42:565-572.

McMurdie, P. J., and Holmes, S. 2013. phyloseq: An R package for reproducible interactive analysis and graphics of microbiome census data. PLoS One 8: e61217.

Michelsen, C. F., Watrous, J., Glaring, M. A., Kersten, R., Koyama, N., Dorrestein, P. C., and Stougaard, P. 2015. Nonribosomal peptides, key biocontrol components for Pseudomonas fluorescens In5, isolated from a Greenlandic suppressive soil. MBio 6:e00079-15.

Munkvold, G. P., and Marois, J. J. 1993. Efficacy of natural epiphytes and colonizers of grapevine pruning wounds for biological control of eutypa dieback. Phytopathology 83:624-629. 
Olanya, O. M., Sites, J. E., and Hoshide, A. K. 2016. Cost modelling of Pseudomonas fluorescens and Pseudomonas chlororaphis as biocontrol for competitive exclusion of Salmonella enterica on tomatoes. Biocontrol Sci. Technol. 26:651-664.

Perazzolli, M., Antonielli, L., Storari, M., Puopolo, G., Pancher, M., Giovannini, O., Pindo, M., and Pertot, I. 2014. Resilience of the natural phyllosphere microbiota of the grapevine to chemical and biological pesticides. Appl. Environ. Microbiol. 80:3585-3596.

Perring, T. M., Farrar, C. A., and Blua, M. J. 2001. Proximity to citrus influences Pierce's disease in Temecula Valley vineyards. Calif. Agric. 55:13-18.

Pieterse, C. M. J., vanWees, S. C. M., Hoffland, E., vanPelt, J. A., and vanLoon, L. C. 1996. Systemic resistance in Arabidopsis induced by biocontrol bacteria is independent of salicylic acid accumulation and pathogenesis-related gene expression. Plant Cell 8:1225-1237.

Pieterse, C. M. J., Zamioudis, C., Berendsen, R. L., Weller, D. M., Van Wees, S. C. M., and Bakker, P. A. H. M. 2014. Induced systemic resistance by beneficial microbes. Annu. Rev. Phytopathol. 52:347-375.

Pinto, C., Pinho, D., Sousa, S., Pinheiro, M., Egas, C., and Gomes, A. C. 2014. Unravelling the diversity of grapevine microbiome. PLoS One 9:e85622.

Porras-Alfaro, A., and Bayman, P. 2011. Hidden fungi, emergent properties: Endophytes and microbiomes. Annu. Rev. Phytopathol. 49:291-315.

Pouzoulet, J., Pivovaroff, A. L., Santiago, L. S., and Rolshausen, P. E. 2014. Can vessel dimension explain tolerance toward fungal vascular wilt diseases in woody plants? Lessons from Dutch elm disease and esca disease in grapevine. Front. Plant Sci. 5:253.

Rastogi, G., Coaker, G. L., and Leveau, J. H. J. 2013. New insights into the structure and function of phyllosphere microbiota through high-throughput molecular approaches. FEMS Microbiol. Lett. 348:1-10.

Rezzonico, F., Zala, M., Keel, C., Duffy, B., Moenne-Loccoz, Y., and Defago, G. 2007. Is the ability of biocontrol fluorescent pseudomonads to produce the antifungal metabolite 2,4-diacetylphloroglucinol really synonymous with higher plant protection? New Phytol. 173:861-872.

Roper, M. C., Greve, L. C., Warren, J. G., Labavitch, J. M., and Kirkpatrick, B. C. 2007. Xylella fastidiosa requires polygalacturonase for colonization and pathogenicity in Vitis vinifera grapevines. Mol. Plant-Microbe Interact. 20:411-419.

Roper, M. C., and Lindow, S. E. 2015. Xylella fastidiosa: Insights Into the Lifestyle of a Xylem-Limited Bacterium. American Phytopathological Society, St. Paul, MN.

Ruegger, P. M., Clark, R. T., Weger, J. R., Braun, J., and Borneman, J. 2014. Improved resolution of bacteria by high throughput sequence analysis of the rRNA internal transcribed spacer. J. Microbiol. Methods 105:82-87.

Samavat, S., Heydari, A., Zamanizadeh, H. R., Rezaee, S., and Aliabadi, A. A. 2014. A comparison between Pseudomonas aureofaciens (chlororaphis) and P. fluorescens in biological control of cotton seedling damping-off disease. J. Plant Prot. Res. 54:115-121.

Saponari, M., Boscia, D., Nigro, F., and Martelli, G. P. 2013. Identification of DNA sequences related to Xylella fastidiosa in oleander, almond and olive trees exhibiting leaf scorch symptoms in Apulia (Southern Italy). J. Plant Pathol. 95:668.

Sessitsch, A., Hardoim, P., Doring, J., Weilharter, A., Krause, A., Woyke, T., Mitter, B., Hauberg-Lotte, L., Friedrich, F., Rahalkar, M., Hurek, T., Sarkar,
A., Bodrossy, L., van Overbeek, L., Brar, D., van Elsas, J. D., and ReinholdHurek, B. 2012. Functional characteristics of an endophyte community colonizing rice roots as revealed by metagenomic analysis. Mol. PlantMicrobe Interact.25:28-36.

Shen, X., Hu, H., Peng, H., Wang, W., and Zhang, X. 2013. Comparative genomic analysis of four representative plant growth-promoting rhizobacteria in Pseudomonas. BMC Genomics 14:271.

Shoresh, M., Harman, G. E., and Mastouri, F. 2010. Induced systemic resistance and plant responses to fungal biocontrol agents. Annu. Rev. Phytopathol. 48: 21-43.

Srinivasan, K., Gilardi, G., Garibaldi, A., and Gullino, M. L. 2009. Efficacy of bacterial antagonists and different commercial products against Fusarium wilt on rocket. Phytoparasitica 37:179-188.

Sun, Q., Sun, Y. L., Walker, M. A., and Labavitch, J. M. 2013. Vascular occlusions in grapevines with Pierce's disease make disease symptom development worse. Plant Physiol. 161:1529-1541.

Tamura, K., and Nei, M. 1993. Estimation of the number of nucleotide substitutions in the control region of mitochondrial-DNA in humans and chimpanzees. Mol. Biol. Evol. 10:512-526.

Triki, M. A., Hadj-Taieb, S. K., Mellouli, I. H., Rhouma, A., Gdoura, R., and Hassairi, A. 2012. Identification and screening of bacterial isolates from Saharan weeds for Verticillium dahliae control. J. Plant Pathol. 94:305-311.

Tumber, K. P., Alston, J. M., and Fuller, K. B. 2014. Pierce's disease costs California \$104 million per year. Calif. Agric. 68:20-29.

Turner, T. R., James, E. K., and Poole, P. S. 2013. The plant microbiome. Genome Biol. 14:209.

van der Heijden, M. G. A., and Schlaeppi, K. 2015. Root surface as a frontier for plant microbiome research. Proc. Natl. Acad. Sci. USA 112:2299-2300.

Varela, L. G., Smith, R. J., and Phillips, P. A. 2001. Pierce's Disease. University of California Agricultural and Natural Resources, Publication 21600, Oakland, CA.

Vorholt, J. A. 2012. Microbial life in the phyllosphere. Nat. Rev. Microbiol. 10: 828-840.

Wang, Q., Garrity, G. M., Tiedje, J. M., and Cole, J. R. 2007. Naive Bayesian classifier for rapid assignment of rRNA sequences into the new bacterial taxonomy. Appl. Environ. Microbiol. 73:5261-5267.

Wells, J. M., Raju, B. C., Hung, H. Y., Weisburg, W. G., Mandelcopaul, L., and Brenner, D. J. 1987. Xylella fastidiosa gen. nov., sp. nov.: Gram-negative, xylem-limited, fastidious plant bacteria related to Xanthomonas spp. Int. J. Syst. Bacteriol. 37:136-143.

White, T. J., Bruns, T., Lee, S., and Taylor, J. 1990. Amplification and direct sequencing of fungal ribosomal RNA genes for phylogenetics. Pages 315-322 in: PCR Protocols: A Guide to Methods and Applications. Academic Press.

Wickham, H. 2009. ggplot2: Elegant Graphics for Data Analysis Introduction. Use R! Springer-Verlag, New York.

Zarraonaindia, I., Owens, S. M., Weisenhorn, P., West, K., Hampton-Marcell, J., Lax, S., Bokulich, N. A., Mills, D. A., Martin, G., Taghavi, S., van der Lelie, D., and Gilbert, J. A. 2015. The soil microbiome influences grapevineassociated microbiota. MBio 6:e02527-14. 